\title{
ГОСУДАРСТВЕННАЯ АГРАРНАЯ ПОЛИТИКА В СИСТЕМЕ АГРАРНОГО ПРОИЗВОДСТВА: ПРОБЛЕМЫ «ПРИЗЕМЛЕНИЯ»
}

\begin{abstract}
Аннотация: В современных условиях организачии и ведения сельскохозяйственного производства государственная аграрная политика реализуется неэффективно. Одним из важнейших факторов повышения ее эффективности является положительное восприятие и осознание важности и значимости иелей, задач, содержания и ожидаемых результатов реализации названной политики на первичном уровне производства непосредственно самими сельхозтоваропроизводителями. Проблема «приземления» аграрной политики приобретает сегодня первостепенное значение. В подавляющем большинстве агрополитические решения принимаются и осуществляются на макроуровне, не доходя до первичного звена производства. Вследствие этого непосредственный сельхозтоваропроизводитель остается вне политического и управленческого воздействия. И как результат, цели аграрной политики не достигаются, задачи не исполняются, не происходит качественных изменений в системе аграрного производства. Повыпение его эффективности и устойчивости видится на пути реализации аграрной политики каждым сельхозтоваропроизводителем, во всех подотраслях сельского хозяйства и агропромышленного комплекса. Назрела необходимость в активизации политической деятельности, направленной на положительное восприятие современной обновленной аграрной политики государства, на формирование доверия к ней. Исследование проведено на основе общенаучных и специальных методов (системный подход, общефилософские методы, исторический метод и др.). Научная новизна исследования заключается в следующем:1. Впервые в современных условиях сформулирована проблема «приземления» государственной аграрной политики, а именно: проблема осознания, восприятия, понимания ее целей и задач непосредственными сельхозтоваропроизводителями и формирования их доверия к названной политике; 2. Впервые сформулированы индикаторы сущности и содержания государственной аграрной политики;3. Даны конкретные предложения по разрешению проблемы «приземления» аграрной политики государства и повышения ее эффективности на уровне первичного сельскохозяйственного производства.Основной вывод: одним из направлений повышения эффективности аграрной политики государства является обеспечение ее реализачии в рамках непосредственного производства всеми сельхозтоваропроизводителями. Только при их доверительном и осознанном отнотении к действиям и решениям государства в аграрной сфере возможны качественные положительные изменения устойчивости и эффективности сельскохозяйственного производства. Abstract: Upon the modern conditions of agricultural production organization, the state agrarian policy is not implemented effectively. One of the most important factors for increasing its efficiency is positive perception and awareness of the importance and significance of the goals, objectives, content and the expected results of implementation of the said policy at the primary production level directly by the agricultural producers. Today, the "landing" of the agrarian policy is paramount. The vast majority of agropolitical solutions are adopted and implemented at the macro level, without reaching the primary production. Consequently, direct agricultural producer is left out from the political and administrative influence. This results in the fact that the objectives of agrarian policy are not reached and its tasks are not fulfilled; there is no qualitative change in the system of agricultural production. Improvement of its efficiency and stability is seen on the way of implementation of agrarian policy by each agricultural producer in all sub-sectors of agriculture and agribusiness. There is a need to revitalize the political activities aimed at the positive perception of the updated modern agricultural policy in order for it to regain trust. We conducted a study on the basis of scientific and special methods (system approach, general philosophical methods, the historical method, etc.). Scientific novelty of the research consists in the following: 1. First time in modern conditions, we formulated the problem of "landing" of the agrarian policy, namely the problem of awareness, perception and understanding of its goals and objectives by direct agricultural producers and their confidence
\end{abstract}


DOI: $10.7256 / 1811-9018.2014 .2 .10691$

При цитировании этой статьи сноска на ооі обязательна

\section{Право и политика $2(170) \cdot 2014$}

in the formation of the said policy; 2. Indicators of essence and content of state agricultural policy formulated for the first time; 3. We offer solutions to solving the problem of "landing" of the agrarian policy of the state and enhancing its efficiency in the primary agricultural production. The main conclusion: in order to increase the efficiency of state agrarian policy we need to ensure its implementation through the direct production by all agricultural producers. Only with their trusting and deliberate attitude towards the actions and decisions of the state concerning the agricultural sector will it be possible to make qualitative positive changes to the stability and efficiency of agricultural production.

Ключевые слова: государство, политика, аграрньй, экономика, производство, восприятие, товаропроизводитель, воля, саморегулирование, реализация.

Keywords: the state, policy, agrarian, economy, production, perception, manufacturer of goods, the will, self-regulation, realization.

B ходе ранее предпринятых нами исследований по аграрной политике государства[1] отмечалось, что в сфере аграрной экономики все более настойчиво обнаруживается тенденция в виде склонности к отрицанию реальной исполнимости решений и постановлений органов власти и хозяйственного управления, направленных на обеспечение устойчивости и эффективности производства. Большинство актов указанных органов под различными предлогами «не замечаются», фактически (DE FACTO), а то открыто (DE VISU), юридически (DE JURE) отвергаются. Эти акты превращаются в нечто формальное, декларативное, ненужное и бесполезное, гестическое (GEEST), абсолютно невыгодное. Такое положение постепенно становится постоянным явлением, увековечивается, генерирует догматизм, перерастающий в волюнтаризм в руководстве сельским хозяйством и АПК. Благое содержание аграрной политики при этом выхолащивается и подменяется субъективным, а именно усмотрением в его негативной разновидности (A DISCRETION), что на деле (IN RE) преобразует политические действия из категории «обязанности» в только «права» (в смысле прав выбора в их общественном понимании со всеми вытекающими отсюда неблагоприятными последствиями: отсталостью, ущербностью, дезорганизованностью, безответственностью, произволом и т.п.). Что очень важно, здесь аграрная политика государства приобретает характер высшего, недоступного для сельских товаропроизводителей обстоятельства и, одновременно, фактора, низводящего их, в первую очередь, крестьянина-производителя, до уровня участника агрохозяйственной деятельности, не заслуживающего внимания.

Все сказанное формирует особую проблему «приземления», приближения требований и содержания названной политики к непосредственному производству, ориентации этой политики на высокие достижения в производстве и повышения качества и уровня жизни на селе. Иными словами сделать ее принадлежностью всего сельского уклада жизни, создать обстановку нетерпимости волюнтаризма в аграрной экономике. Подобное решение проблемы переведет политическую стрелку с «верхов»на «низы», сделав саму аграрную политику достоянием сельских жителей. Особенности социально-экономического строя современной России бескомпромиссно прогнозируют необходимость переноса политического акцента на сферу аграрного производства.

На наш взгляд, нигилистическое отношение к аграрной политике обусловлено сложившейся в течение многих лет ситуацией непризнания вечно действующих начал объективного и универсального закона саморегуляции природы о предопределенности естественных и социальных явлений, подменой его сущностной основы, ложным учением о законах общественного развития[2]. Именно названным законом детерминированы природные и социальные обстоятельства с момента их возникновения (IN STATU NASCENDI), развития (EVOLUTIO) и прекращения бытия (MORS), в том числе и самого общества как социального организма, интегрированного в рамках природно-обусловленного наличествования. Общество, следовательно, есть дитё природы и его субстанция (сущность, относительная самостоятельность) и построение (CONSTITUTIO) еще с рождения, с зародышевого состояния, (YERMINARE) предопределено законом природы. Поэтому и его дальнейшее функционирование может быть осуществлено в форме саморегулирующегося явления действительности, мироздания, через разрешение внутренних, имманентных противоречий. К сожалению, приведенное понимание сущности происходящих в сфере аграрной экономики процессов в контексте регулирования аграрных отношений по ряду причин «забывается», а то и игнорируется, что сопровождается переложением значительной части затрат на производство на плечи государства в форме оказания государственной поддержки сельским товаропроизводителям. Это влечет откаты, взяточничество и другие проявления коррупции и, самое главное, уводит производителей от поиска, 
выявления и использования собственных резервов и возможностей результативного ведения сельскохозяйственного производства. Отрасль постепенно и последовательно теряет способность к снабжению населения и перерабатывающие сельскохозяйственное сырье структур и подотраслей, тем самым формируя импортозависимость страны от зарубежья. На этой почве создаются условия для провокации (PROVOCATIO) и побуждения ущербной агрохозяйственной деятельности, а также формирования особого негативного факта - социального события продовольственной опасности, что подтверждается данными ежеквартальных и ежегодных обзоров экономического состояния агропромышленного производства России, которые свидетельствуют о хроническом спаде производства сельскохозяйственной продукции, росте ее импорта и снижении уровня импортозамещения[3]. Нет сомнения, в генерации (GENERATIO) сокращения объемов производства указанной продукции главную роль играют не отсутствие природно-биологических ресурсов и, даже, не сокращение человеческого потенциалаь (они в стране есть[4]), а, как нам кажется, сформировавшаяся в силу своего многократного повторения за время прошедшего столетия позиция органов власти и агрохозяйственного руководства, основанная на всемогуществе дискреционного управления, другими словами, - умалении возможностей агрополитического воздействия на результаты хозяйствования, навязывании неоправданных, научно необоснованных и непонятных для непосредственных сельскохозяйственных товаропроизводителей реформ, разбазаривании и расхищении, под предлогом банкротства, их имущества.

В озвученном выше контексте в системе мер по выходу из сложившегося положения видится также и в признании концептуального подхода к возможной в будущем редукции (REDUCERE) аграрной политики государства, в приведении ее в деятельностное, работающее состояние, то есть в органической взаимосвязи с непосредственными производителями сельскохозяйственной продукции, при одновременной отмене (ABROGATIO) устаревших политико-правовых актов. Это, по нашему обоснованному убеждению, позволит победить галопирующую (GALOP) ныне продовольственную интервенцию извне с недоброкачественными продуктами и сельскохозяйственным сырьем низкого качества, изжить псевдоностность и квазинаправленность псевдопреобразований, проводимых аграрной экономике страны.

Выдвигаемые до настоящего времени предложения по улучшению политического воздействия на аграрное производство ограничивались вполне благостными советами, рекомендациями и пожеланиями совершенствовать агрохозяйственное планирование в большей части на макроуровне (общефедеральном, редко региональном)[6]. Непосредственные сельхозтоваропроизводители о таких предложениях, как правило, не осведомлены, а если и извещены о них, то не понимают их содержания и целесообразности, не воспринимают их как должное и общеполезное для сельского хозяйства мероприятие.

В результате доминирования (DOMINANTIS) сценарного (SCENARIO), сецессионного (SESESSIO), отступнического образа реализации аграрной политики государства, то есть субъективного, саморегулятивно обусловленного практикой многократного повторения в ходе своего осуществления, ставшего объективной данностью состояния, желаемые цели воздействия государства на агрохозяйственные отношения не достигаются. Политика дистанцируется от собственной первоосновы - аграрной отрасли производства, от активности хозяйствующих на селе субъектов, от их заинтересованности в росте устойчивости и эффективности сельскохозяйственного производства, теряет принадлежащие ей ранее прецессионные (PRAECESSIO) и прогнозно-прогрессивные качества и не может реагировать на изменяющиеся обстоятельства (отставание, отсталость, ущербность хозяйствования и др.), принимать обоснованные по существу позитивные решения.

Между тем, государственная аграрная политика должна отражать присутствующие в ней свойства, охватывающие не столько сферу директивно определяемого воздействия на аграрную экономику, сколько область ее реального бытия и опредмечивания. Она, только в таком понимании, восприятии и легитимации способна открыть путь к эмпирической составляющей аграрной деятельности, создает почву для социального познания агропроизводственного поведения как созидательного, деятельностного явления, лежащего в основе активных форм хозяйствования на селе[7]. В толкуемом смысле, рассматриваемая политика перестанет быть редким, преклюзивным (PRAKLUSION), исключительным явлением и проникнет в повседневную практику работы отрасли. Этим самым будет достигнуто соответствие политических отношений характеру производительных сил современной деревни, что рельефно видно из опыта внутрихозяйственного планирования и саморегулирования сельскохозяйственного производства[7].

По нашему мнению, подобный консенсус (CONSENSUS), возникающий по инициативе самих товаропроизводителей, должен рассматриваться как 
DOI: 10.7256/1811-9018.2014.2.10691

При цитировании этой статьи сноска на dоі обязательна

\section{Право и политика $2(170) \cdot 2014$}

конкретный акт политического влияния на экономические связи, ибо он плодотворен, настойчиво прокладывает дорогу в самое «сердце» сельскохозяйственного производства, занимая достойное место образа жизни (MODUS VIVENDI) в системе агрохозяйственных отношений страны на первичном уровне отраслей производства.

Изложенный выше теоретико-эмпирический очерк агрополитического воздействия на сельскохозяйственное производство показывает служебную роль, которую выполняет государственная аграрная политика в организационном обеспечении сельского хозяйства, в частности, ее «обязательственные» возможности в стимулировании и дальнейшем росте рачительного воспроизводства сельскохозяйственной продукции в реальной самобытности и осуществлении. Роль государственной аграрной политики в «ипостаси» (в контексте рыночных, саморегулирующихся требований) должны лигитимироваться, что на деле (IN RE) возможно лишь при признании ряда сопровождающих политику обстоятельств в качестве оснований становления и бытия индикаторов ее сущности и содержания. К числу упомянутых обстоятельств следует отнести:

а) наличие естественно осознанной, сформировавшейся под влиянием необходимости удовлетворения имущественного интереса, воли участвовать в производстве сельскохозяйственной продукции;

б) определенность содержания такой воли в соответствии с правилами установленных государством агрополитического и правового режимов;

в) охватываемые сознанием и волей предпочтительность (PRAEFERENS) агропроизводственных действий, реальная возможность их наступления, достаточная и разумная подвижность, даже при наступлении так называемой невозможности исполнения (TRANSTULISTI), трансцендетальность;

г) устойчивость бытия, обладание постоянством, «вечностью» в рамках константности существования хозяйственной деятельности в пространстве и во времени, в смысле субстанциональности сущего, а также принадлежность к конкретным, дискретным разновидностям возобновляющихся актов хозяйствования, непосредственных действий воспроизводства сельскохозяйственных продуктов и их обмена.

Практика хозяйствования на селе подтверждает объективно существующую необходимость в проявлении должной реакции на перечисленные и им подобные обстоятельства при организационном обеспечении сельскохозяйственного производства. Вся совокупность этих обстоятельств должна быть ориентирована на побуждение производителей к созидательному труду, использованию их субъективного, духовного капитала на достижение высоких производственных показателей хозяйствования.

Утвердившаяся к настоящему времени нужда в надлежащем восприятии основ аграрной политики на первичном уровне производства требует обязательного учета перечисленных выше обстоятельств. При этом следует понимать, что названная политика не должна восприниматься только как результат абстрагирования от возможных способов ее «осуществления», а должны пониматься как волевое отношение государства к аграрным связям, закрепляемым в соответствующих их содержанию социальных решениях и установлениях, в большинстве лигитимируемых в нормативных актах, в том числе и в локальных актах внутрихозяйственного планирования и саморегулирования[7]. Проблема «приземления» аграрной политики, к сожалению, стагнируется на высшем уровне, нужны другие, более надежные, средства ее решения, такие, как акты инициативного порядка, то есть акты саморегулирования (самоорганизации) агрохозяйственной деятельности, которые в хозяйствах ряда регионов федерации начинают занимать преобразующее положение в системе неюридического воздействия на сельскохозяйственное производство. Подобная, инициативно возникающая в недрах сельской отрасли производства форма саморегулирования, презентирующаяся в виде неформализованного объединения сельских жителей и других граждан для ведения сельского хозяйства, отражает все отмеченные выше обстоятельства (индикаторы) образования (создания) и функционирования. Объединение формируется исключительно по воле членов групп инициативных производителей (ГИП) продукции в целях достижения и роста устойчивости и эффективности производства сельскохозяйственной продукции высокого качества, то есть осознанно, на материально заинтересованной основе. Деятельность ГИП строится на познании реально существующей, объективной возможности осуществления производства не предпочтительной, активной и доходной основе; на определенности содержания усмотрением, недопустимости некомпетентного вмешательства извне и, даже, со стороны органов управления хозяйств-непосредственных товаропроизводителей, самоуправляемости, устойчивости позиции в системах агрохозяйственной деятельности отрасли в целом и конкретных хозяйств-юридических лиц[7].

Саморегулируемая деятельность ГИП-оптимальная организационно-правовая форма сельских товаропроизводителей. В сложившихся условиях отставания и 
наступившей отсталости всей аграрной отрасли страны она достойна всевозможной политической поддержки и законодательного признания, причем, в первую очередь, в контексте «приземления», удовлетворения интересов непосредственных сельских товаропроизводителей. На таком, во многом поддерживаемом политическом подходе, основано производство и зиждется годами выращивание сахарной свеклы, сортового картофеля в северных районах Республики Башкортостан, заготовка кормов и кормообеспечения животноводства, откорм молодняка крупного рогатого скота, доение коров, пастьба поголовья. В 2013 году, например, земледельцы Мелеузовского района республики, несмотря на тяжелую засуху, смогли получить рекордные урожаи зерна (22 ц/га), сладких корнеплодов (35 т/га), подсолнечника $(19$ ц/га)[8]. На нем же основывается природно обусловленный и осознанный непосредственными сельскими товаропроизводителями расчет, держится обновление природно-племенного состава коров[9]; реализуется, в основном, технико-технологическая модернизация конкретной материальной и сервисной базы отдельных хозяйств региона[10]; упрочивается организационноправовая и кадровая составляющая аграрного производства на первичном уровне[11]. В результате предпринятых мер по активизации и усилению массовости политической работы аграрная политика государства все более и более становится «непосредственной данностью» сельскохозяйственного производства, надежным инструментом воздействия на созидательную часть последнего. И, как итог разумной приверженности к сфере подготовленной и целесообразной деятельности, политика получает способность к генерированию доходных форм хозяйствования на селе, а в конечном счете - формой общеполезного событийно предопределенного[12], политического поведения. Именно таковое произошло и происходит в агропроме Башкортостана, где, даже в аномальном биоклиматическом отношении 2013 году аграрии получили валовой продукции растениеводства без малого на пятую часть больше, чем в 2012 году, а в денежном выражении, определяемом по итогам трех кварталов текущего года, более 39 млрд. рублей. В целом (EN MASSE) к концу 2013 года валовая продукция регионального АПК обещает быть более ста млрд. рублей[13], заметное место в получении которых принадлежит политико-организационному фактору.

Агрополитическая деятельность - сложная форма государственной политики. Она - явление реальной действительности, композиционно стабилизирующееся (STABILIUS), закрепляющееся на определенном, аграрном уровне общественного производства, структурно (STRUCTURA) субстантивирующееся (SUBSTANTIVUS), обладающее разновидностными особенностями (DIFFERENTIA SPECIFICA). По данным причинам к ней можно и следует отнестись с указанной, дефинитивной (DEFINITIO) позиции (POSITIO) допустимости и оппозиции (OPPOSITIO), представлять ее и воспринимать как нечто объективирующееся во вне в виде находящейся в бинарной оппозиции наличности. B своем формировании (FORMARE), образовании, достижении полной зрелости и окончательного развития эта деятельность всецело зависит от требований закона саморазвития природы, касающихся духовной жизни человеческого общества, его политико-правового регулирования. Это означает, что проблема «приземления» должна, прежде всего, иметь собственное пространство (LOCUS - область социально-экономических действий, собственные реальные возможности к редукции, преобразованию субъективного, догматического, в объективное) и время (TIME) существования. Ныне эти индикаторы, определяющие положение аграрной политики, частично либо полностью устойчиво игнорируются.

Пространство политических действий обычно не затрагивает поле непосредственных сельских товаропроизводителей, оставаясь, как правило, на уровне функционирования федеральных и региональных властей агрохозяйственного управления в виде советов и рекомендаций (PIA DESIDERIA), а также паллиативных (PALLIATIF) решений. Что касается времени существования аграрной политики, то оно относилось только ко всему периоду догматического управления сельской отраслью, не затрагивая временную определенность непосредственных производителей.

В предыдущем столетии редукции субъективного в объективное в системе аграрной политики места не оставалось, об этом вообще не задумывались.

Таким образом, упрочение аграрной политики в понимаемом здесь смысле достигаемо в жизни лишь в условиях объективно существующих возможностей и волевого опосредования доходности аграрного труда и производства, осознания их участниками важности, необходимости и предметности бытия. Иное не приведет к желаемой результативности, ибо «IMPOSSIBILIUM NULLA EST OBLIGATIO» («нет обязательства, если предмет невозможен, добавим от себя, вследствие физических, правовых и моральных причин»). Неподвижность обязательства, по каким бы обстоятельствам она не консолидировалась (CONSOLIDARE), не может и не должна стать терпимой, что реализуемо лишь при надлежащем ответственном выборе исполнителя агрополитической деятельности, его подго- 
DOI: 10.7256/1811-9018.2014.2.10691

При цитировании этой статьи сноска на dоі обязательна

\section{Право и политика $2(170) \cdot 2014$}

товленности и готовности к совершению действий по производству продукции в режимах, установленных государством и другими политическими акторами, с должной заботливостью на уровне всякого среднего человека (DILIGENTISSIMUS), «принадлежностно» к правилам агрополитического регламентирования, усвоением ими норм агрополитического поведения до степени естественности автоматизма. Как показывает практика хозяйствования на селе, данной стороной исследуемой нами проблемы (из-за оттока кадров из села, отсутствия жилья, зарплаты, профессиональных навыков к сельскому труду, недостатков социального обеспечения и т.п.) мало кто занимается. Но там, где уделяется достаточно внимания проблеме, осуществляется подлинная реорганизация хозяйств в форме присоединения убыточных предприятий и организаций к состоятельным, вместо применяемого при советской власти укрупнения колхозов и совхозов путем переноса целых деревень к центрам хозяйств, способствование развитию индивидуального жилищного строительства, возведение объектов образования, здравоохранения, оказание бесплатной материальной помощи по обзаведению животными, кормами для них, обеспечение всего того, что называется «вниканием в вопросы бытового и социального значения», результативность усилий окупается предельно быстро.

В стране ведется ограниченная, слабая по содержанию и форме экономико-правовая пропаганда основ аграрного производства и его политического обеспечения, тогда как оболванивающие сельское население, да и все население страны, низкопробные, далекие от подлинной человеческой культуры, передачи средств массовой информации льются рекой. Происходит это потому, что пропаганда аграрного не переходит в направленную агитациию. Сельский товаропроизводитель предоставлен самому себе, природная приверженность его к сельскому образу жизни не приветствуется. Кино- и телефильмы демонстрируют разрушенные деревни. Одним словом, отсутствует целенаправленное воспитание сельского жителя в духе важности сельскохозяйственного труда на показательных примерах и достижениях. Все это снижает значимость массовой политической работы, отдаляя крестьянина от сферы действия аграрной политики и инициируя его безразличие к аграрным реформам и преобразованиям.

Аргументов, подтверждающих наличие индикативных обстоятельств, лежащих в основе сущности и содержания регулятивных свойств аграрной политики, достаточно много и можно их перечислять до бесконечности (AD INFINITUM). Тем не менее для обоснования положений, в обозначенных выше литерах, следует сослаться еще на некоторые из них, взятые по выбору (AD LIBITUM). В приведенном плане достоин внимания тот факт, что в угоду интересам правящей элиты представлялись содержательно искаженные и ложные реляции (RELATIO) о не имеющихся достижениях в аграрном производстве, искаженные отчеты о причинах невыполнения заданий и директив, организовывались мероприятия показушно-триумфального характера и содержания, например, выступления в печати о сборе 1 миллиарда пудов хлеба в Казахстане в бытность Д. Кунаева первым секретарем ЦК Компартии Казахстана (так надо, пуд, а не тонна, звучит громко и подкупающе). Аналогичное же имело место в Узбекистане в сфере производства и сбора хлопка-сырца, впоследствии были обнаружены приписки. Такой же чертой обладала и имевшая место при Н.С. Хрущеве целинная эпопея, закончившаяся провалом, эрозией почв, опустыниванием, потерей естественного плодородия. В настоящее время подобное в проводимой аграрной политике тоже имеет место. Отчеты о выполнении агрохозяйственных обязательств преднамеренно искажаются, объемы сборов сельскохозяйственной продукции, указанные в официальных источниках, отчасти не соответствуют действительности. В итоге, тем самым, стимулируется импорт продовольствия; отрасль, при существующей отечественной безработице, работает на трудообеспечение населения зарубежья. И происходит все описанное здесь, главным образом, из-за несовершенства аграрной политики, отсутствия ее «приземленности», и восприятия непосредственными сельскими товаропроизводителям; из-за игнорирования индикаторов ее неустойчивости, обозначенной в контексте, изложенном выше под литером «г» данной статьи. Процесс формирования аполитичности завершается зарождением социального события - неведения, ущербного для аграрной экономики безразличия, бездействия.

Аграрная политика государства на первичном уровне производства должна объективироваться как перманентное явление действительности. Первичный уровень производства требует, чтобы разработанные верхними эшелонами власти и агрохозяйственного управления решения переходили в реальное состояние аграрной экономики, воспринимались непосредственными товаропроизводителями, выполнялись с учетом специфики хозяйствования, обусловленной биоклиматической сущностью сельскохозяйственного производства, возможностями проявления его разумной подвижности. Навязывание иных, противоречащих требованию саморегулятивности отношений, 
недопустимо, ибо это может привести к неприятию всего и всякого политического на изначальном уровне осуществления сельского хозяйства, утрате веры в сельскохозяйственный труд.

Наконец, агрополитическое регулирование производственных отношений на селе мыслимо только в ключе всеобщности охвата сельскохозяйственной и агропромышленной деятельности (SUB SPECIE AETERNITATIS), ибо человеческое общество не может не заниматься растениеводством и разведением животных, являющихся основой продовольственного обеспечения населения страны.

«Привитие» аграрной политики уровню сельскохозяйственного производства - деятельность многосторонняя, требующая привлечения огромных сил и средств. Эта деятельность одновременно является идеологической, организационной, экономической (ресурсной), правовой и, конечно же, политической, мобилизационной, научно обосновываемой, что обязательно должно быть учтено и легитимировано при разработке соответствующих ее содержанию общегосударственных и общехозяйственных, а также первоуровневых мероприятий (при принятии бюджетов, стратегий, целевых программ, составления бизнес-планов хозяйств, модернизации техники и технологий, внедрении научных достижений в производство, воспроизводстве кадров и т.д.).

Вышеизложенные аргументы в пользу становления и развития аграрной политики государства в направлении первичного звена сельского хозяйства и АПК страны, как нам кажется, являются основаниями для следующих выводов и предложений:

1. Действующая в настоящее время аграрная политика государства не отражает и не выражает требования всеобщего (всеохватывающего) универсального, единственного и единого закона саморегуляции (саморазвития, самоорганизации) природы;

2. Структурно она несовершенна, излишне отрицательно догматична и волюнтаристична, ущербна, ориентирована на обеспечение устойчивости и эффективности аграрного производства путем задействования, главным образом, материальнотехнических ресурсов государства и, как следствие этого, не имеет специальной части, направленной на мобилизацию естественно обусловленных возможностей непосредственных товаропроизводителей, а также и части, посвященной активизации агрохозяйственной деятельности последних;

3. Указанные в п.2 недостатки генерируют фиксацию правил аграрной политики на федеральном и региональном уровнях, оставляя эти правила вне непосредственного производства, чем закладываются реальные условия для нарушения возможного в будущем единства структурных составляющих политики;

4. Существующая аграрная политика государства дискретна и депрессивна, подавляют инициативу товаропроизводителей, субъективна, антиредукционна, препятствует прогрессу в аграрной экономике, в сельскохозяйственном производстве, в частности, редукции (приведению) субъективного в объективное состояние, закрепляет в сельском хозяйстве дискретный стиль управления на первичном уровне производства, препятствует саморегулированию;

5. Рассматриваемая политика нуждается в немедленном «приземлении» в программном-целевом режиме, признании относительной (внутренней) самостоятельности ее первичного уровня бытия и, одновременно, наличия единства существования в рамках всей целостной структуры, взаимосвязи с высшими уровнями системы, объявлялении ее всенародным делом России, что повысит роль сельских товаропроизводителей в организации производства, социальном развитии и культуре, профессиональном мастерстве, ответственности за результаты созидательной деятельности;

6. Необходимо разработать и принять Государственную аграрную политику, предусматривающую подобающее место политико-правового статуса непосредственных сельских товаропроизводителей, их инициативно возникающих формирований;

7. Требуется системное проведение политической пропагандистской, агитационной и воспитательной деятельности, направленной на осознание, восприятие, понимание сельхозтоваропроизводителями современной обновленной аграрной политики государства, на повышение их доверия к ней.

\section{Библиография:}

1. Ханнанова Т.Р. Государственная аграрная политика: проблемы объективации // Право и политика. 2013. № 4. С. 489-498; ее же. Реализация аграрной политики государства: принципиальные основы // Политика и общество. 2013. № 5. С. 630-639 и др.

2. Ханнанов Р.А., Ханнанова Т.Р. Модернизация государственной агарной политики. - Уфа, АН 


\section{Право и политика $2(170) \cdot 2014$}

РБ, БГАУ ГУП РБ Уфимский полиграфкомбинат. - 483 c. - C. 9-39.

3. Ханнанова Т.Р. Государственная аграрная политика: проблемы объективации. // Право и политика. 2013. № 5. С. 489-498.

4. Шутьков А. Аграрная политика: социально-экономические проблемы // АПК: экономика, управление. 2011. № 5. С. 8-9; Алтухов А. Новые проблемы развития зерновой отрасли // АПК: экономика, управление. 2011. № 5. 2011. № 1. С. 11, 14-15;

5. Буздалов И. Земельная реформа: взгляд сквозь призму замысла // АПК: экономика, управление. 2011. 2011. № 7. С. 17;

6. Куликов И. Инновационная стратегия как фактор преодоления аграрного кризиса // АПК: экономика, управление. 2011. № 5. С. 3-10;

7. Ханнанова Т.Р. Становление и развитие государственной аграрной политики: сравнительный индикативный анализ. // Политика и общество. 2013. № 3. С. 282-293.

8. Ханнанов Р.А. Проблемы правового обеспечения внутрихозяйственного планирования и саморегулирования // Право и политика. 2012. № 6. С. 1046-1063.

9. Политавкин С., Ихияров И. Мелеузовцы не подкачали // Республика Башкортостан. 2013. 7 ноября. C. 2.9 .

10. Ахияров И. Директор в промышленной спецовке // Республика Башкортостан. 2013. 7 ноября. С. 2.

11. Круглова Т. Сила «Дружбы»// Республика Башкортостан. 2013. 7 ноября. С. 3.

12. Ханнанов Р.А., Ханнанова Т.Р. События в системе правового обеспечения модернизации социальноэкономического развития России: теория и практика. // Уфа, Башкирский ГАУ, АН РБ, 2012. - 162 c. - С. 103-104.

13. Ахияров И. Закаленные засухой // Республика Башкортостан. 2013. 7 ноября. С. 1.

14. Волох В.А., Герасимова И.В. Экономические эффекты от реализации государственной миграционной политики Российской Федерации. // NB: Экономика, тренды и управление. - 2014. - 1. - C. 1 - 12. URL: http://www.e-notabene.ru/etc/ article_9629.html

\section{References (transliteration):}

1. Khannanova T.R. Gosudarstvennayaagrarnaya politika:problemy ob"ektivatsii// Pravo i politika. 2013. №4. S. 489-498; ee zhe. Realizatsiya agrarnoi politiki gosudarstva: printsipial'nye osnovy // Politika i obshchestvo. 2013. № 5. S. 630-639 i dr.

2. Khannanov R.A., Khannanova T.R. Modernizatsiya gosudarstvennoi agarnoi politiki. - Ufa, AN RB, BGAU GUP RB Ufimskii poligrafkombinat. - 483 s. - S. 9-39.

3. Khannanova T.R. Gosudarstvennayaagrarnaya politika:problemy ob"ektivatsii. // Pravo i politika. 2013. № 5. S. 489-498.

4. Shut'kov A. Agrarnaya politika: sotsial'no-ekonomicheskie problemy // APK: ekonomika, upravlenie. 2011. № 5. S. 8-9; Altukhov A. Novye problemy razvitiya zernovoi otrasli // APK: ekonomika, upravlenie. 2011. № 5. 2011. № 1. S. 11, 14-15;

5. Buzdalov I. Zemel'naya reforma: vzglyad skvoz' prizmu zamysla// APK: ekonomika, upravlenie. 2011.2011. № 7. S. 17;

6. Kulikov I. Innovatsionnaya strategiya kak faktor preodoleniya agrarnogo krizisa // APK: ekonomika, upravlenie. 2011. № 5. S. 3-10;

7. Khannanova T.R. Stanovlenie i razvitie gosudarstvennoi agrarnoi politiki: sravnitel'nyi indikativnyi analiz. // Politika i obshchestvo. 2013. № 3. S. 282-293.

8. Khannanov R.A. Problemy pravovogo obespecheniya vnutrikhozyaistvennogo planirovaniya i samoregulirovaniya // Pravo i politika. 2012. № 6. S. 1046-1063.

9. Politavkin S., Ikhiyarov I. Meleuzovtsy ne podkachali // Respublika Bashkortostan. 2013. 7 noyabrya. S. 2. 9.

10. Akhiyarov I. Direktor v promyshlennoi spetsovke // Respublika Bashkortostan. 2013. 7 noyabrya. S. 2.

11. Kruglova T. Sila «Druzhby» // Respublika Bashkortostan. 2013. 7 noyabrya. S. 3.

12. Khannanov R.A., Khannanova T.R. Sobytiya v sisteme pravovogo obespecheniya modernizatsii sotsial'no-ekonomicheskogo razvitiya Rossii: teoriya i praktika. // Ufa, Bashkirskii GAU, AN RB, 2012. - 162 s. - S. 103-104.

13. Akhiyarov I. Zakalennye zasukhoi // Respublika Bashkortostan. 2013. 7 noyabrya. S. 1.

14. Volokh V.A., Gerasimova I.V. Ekonomicheskie effekty ot realizatsii gosudarstvennoi migratsionnoi politiki Rossiiskoi Federatsii. // NB: Ekonomika, trendy i upravlenie. - 2014. - 1. - C. 1 - 12. URL: http://www.enotabene.ru/etc/article_9629.html 